\title{
Salience attribution and its relationship to cannabis-induced psychotic symptoms
}

\author{
M. A. P. Bloomfield ${ }^{1,2,3}$, E. Mouchlianitis ${ }^{1,2}$, C. J. A. Morgan ${ }^{4,5}$, T. P. Freeman ${ }^{4}$, H. V. Curran ${ }^{4}$, \\ J. P. Roiser ${ }^{6}$ and O. D. Howes ${ }^{1,2 *}$ \\ ${ }^{1}$ Psychiatric Imaging Group, MRC Clinical Sciences Centre, Institute of Clinical Sciences, Hammersmith Hospital, Imperial College London, Du \\ Cane Road, London W12 0NN, UK \\ ${ }^{2}$ Department of Psychosis Studies, Institute of Psychiatry, Psychology \& Neuroscience, King's College London, De Crespigny Park, London SE5 8AF, \\ UK \\ ${ }^{3}$ Division of Psychiatry, University College London, 6th Floor Maple House, 149 Tottenham Court Road, London W1T 7NF, UK \\ ${ }^{4}$ Clinical Psychopharmacology Unit, Research Department of Clinical, Educational and Health Psychology, University College London, 4th Floor, 1- \\ 19 Torrington Place, London WC1E 7HB, UK \\ ${ }^{5}$ Washington Singer Laboratories, Department of Psychology, University of Exeter, Exeter EX4 4QG, UK \\ ${ }^{6}$ Institute of Cognitive Neuroscience, University College London, 17 Queen Square, London WC1N 3AR, UK
}

Background. Cannabis is a widely used drug associated with increased risk for psychosis. The dopamine hypothesis of psychosis postulates that altered salience processing leads to psychosis. We therefore tested the hypothesis that cannabis users exhibit aberrant salience and explored the relationship between aberrant salience and dopamine synthesis capacity.

Method. We tested 17 cannabis users and 17 age- and sex-matched non-user controls using the Salience Attribution Test, a probabilistic reward-learning task. Within users, cannabis-induced psychotic symptoms were measured with the Psychotomimetic States Inventory. Dopamine synthesis capacity, indexed as the influx rate constant $K_{i}^{c e r}$, was measured in 10 users and six controls with 3,4-dihydroxy-6-[ $\left[{ }^{18} \mathrm{~F}\right]$ fluoro-L-phenylalanine positron emission tomography.

Results. There was no significant difference in aberrant salience between the groups $\left[F_{1,32}=1.12, p=0.30\right.$ (implicit); $F_{1,32}$ $=1.09, p=0.30$ (explicit)]. Within users there was a significant positive relationship between cannabis-induced psychotic symptom severity and explicit aberrant salience scores $(r=0.61, p=0.04)$ and there was a significant association between cannabis dependency/abuse status and high implicit aberrant salience scores $\left(F_{1,15}=5.8, p=0.03\right)$. Within controls, implicit aberrant salience was inversely correlated with whole striatal dopamine synthesis capacity $(r=-0.91, p=0.01)$, whereas this relationship was non-significant within users (difference between correlations: $Z=-2.05, p=0.04$ ).

Conclusions. Aberrant salience is positively associated with cannabis-induced psychotic symptom severity, but is not seen in cannabis users overall. This is consistent with the hypothesis that the link between cannabis use and psychosis involves alterations in salience processing. Longitudinal studies are needed to determine whether these cognitive abnormalities are pre-existing or caused by long-term cannabis use.

Received 4 July 2016; Revised 22 July 2016; Accepted 25 July 2016; First published online 15 September 2016

Key words: Addiction, cannabis, dopamine, psychosis, salience.

\section{Introduction}

Cannabis is a widely used drug (United Nations Office on Drugs and Crime, 2010) and cannabis may disrupt reward-based learning (Mendelson et al. 1976; Cherek et al. 2002; Lane \& Cherek, 2002; Lane et al. 2005). The main psychoactive substance in cannabis is $\Delta^{9}$-tetrahydrocannabinol (THC) (Wachtel et al. 2002), an endocannbinoid $\mathrm{CB}_{1}$ receptor partial agonist

* Address for correspondence: O. D. Howes, D.M., Ph.D., M.A., B. M., B.Ch., MRC.Psych., Psychiatric Imaging Group, MRC Clinical Sciences Centre, Hammersmith Hospital, Imperial College London, Du Cane Road, London W12 0NN, UK.

(Email: oliver.howes@csc.mrc.ac.uk)
(Felder et al. 1992; Sim et al. 1996; Petitet et al. 1998; Shen \& Thayer, 1999; Breivogel \& Childers, 2000; Govaerts et al. 2004; Kelley \& Thayer, 2004; Paronis et al. 2012). Human and animal research indicates that THC can disrupt reward-based behaviour (Stiglick \& Kalant, 1983; Foltin et al. 1989; Kamien et al. 1994; Lane \& Cherek, 2002; Lane et al. 2004). The mesolimbic dopamine system mediates rewardbased learning (Berridge \& Robinson, 1998), which in turn is modulated by the endocannabinoid system (Fernandez-Ruiz et al. 2010; Melis \& Pistis, 2012; Melis et al. 2012).

THC has complex effects on the dopamine system: studies in rodents indicate that acute administration increases dopaminergic neuron firing rates (French,

This is an Open Access article, distributed under the terms of the Creative Commons Attribution licence (http://creativecommons.org/licenses/by/4.0/), which permits unrestricted re-use, distribution, and reproduction in any medium, provided the original work is properly cited. 
1997); whilst chronic administration reduces presynaptic dopaminergic function (Ginovart et al. 2012). In humans, acute THC administration has been reported to increase dopamine release in two out of four studies (Bossong et al. 2009; Stokes et al. 2009; Barkus et al. 2011; Kuepper et al. 2013), whilst chronic cannabis use is associated with reductions in dopaminergic function (Urban et al. 2012; Albrecht et al. 2013; Bloomfield et al. 2014a, b; Volkow et al. 2014). There is also evidence that long-term cannabis use is associated with attenuated striatal reward processing (van Hell et al. 2010). These studies provide converging evidence that cannabis use disrupts reward-based learning by changes to the dopaminergic system.

Cannabis users are dose-dependently at increased risk of schizophrenia (Murray et al. in press). Psychosis has been proposed to reflect a state of aberrant salience processing driven by elevated dopamine transmission (Kapur, 2003), and aberrant salience has been related to the presence of delusions in medicated patients with schizophrenia (Roiser et al. 2009). Similarly, individuals at ultra-high risk of psychosis demonstrate aberrant salience, the degree of which relates to the severity of delusion-like symptoms (Roiser et al. 2013). Since longterm, regular cannabis use is associated with increased risk of psychosis (Murray et al. in press), the aberrant salience hypothesis predicts that aberrant salience processing is elevated in this group and that this is linked to the induction of psychotic-like symptoms in cannabis users.

Therefore, we sought to investigate reward-based salience processing in cannabis users using the Salience Attribution Test (SAT) (Roiser et al. 2009). The SAT is a probabilistic reward-learning task featuring compound cue stimuli that vary along two dimensions, one task-relevant and one task-irrelevant. 'Adaptive' reward learning refers to differences in ratings (the explicit measure of learning) and reaction times (RTs) (the implicit measure of learning) along the task-relevant cue dimension, i.e. for high-probability reward cue features relative to low-probability reward cue features. 'Aberrant' reward learning is defined similarly, but along the task-irrelevant dimension, i.e. differences in ratings or RTs between cue features that are both associated with $50 \%$ probability of reward.

We hypothesized that cannabis users would show elevated levels of aberrant salience compared with non-user controls, and that within the cannabis users aberrant salience processing would be specifically associated with greater severity of transient psychotic phenomena. We also sought to explore whether users who meet diagnostic criteria for cannabis dependence or abuse [Diagnostic and Statistical Manual of Mental Disorders, fourth edition, text revision (DSM-IV-TR) 304.30; 305.20, i.e. compulsive or periodic harmful use of cannabis despite significant drug-related problems] would exhibit elevated aberrant salience processing. As a number of participants had previously undergone 3,4-dihydroxy6- $\left[{ }^{18} \mathrm{~F}\right]$ fluoro-L-phenylalanine $\left(\left[{ }^{18} \mathrm{~F}\right] \mathrm{DOPA}\right)$ positron emission tomography (PET) in this laboratory (Bloomfield et al. 2014a, b), we also sought to explore the relationships between dopamine synthesis capacity and aberrant salience processing.

\section{Method}

\section{Study population}

The study was approved by the National Research Ethics Service (Research Committee Reference 10/ $\mathrm{H} 0713 / 56)$ and conducted in accordance with the Declaration of Helsinki. All participants provided informed written consent to participate and received a modest financial reimbursement for their time.

Inclusion criteria for all participants were: minimum age of 18 years and capacity to give written informed consent. Exclusion criteria for all participants were: current or past psychiatric illness (excluding cannabis use disorders in the cannabis group) using the Structured Clinical Interview for DSM-IV (SCID) (First et al. 1996); family history of mental illness in a first-degree relative determined via the Family Interview for Genetic Studies (NIMH Genetics Initiative, 1992); evidence of an at-risk mental state for psychosis (Phillips et al. 2000); DSM-IV-TR (American Psychiatric Association, 2005) substance dependency or abuse (other than cannabis in the cannabis-user group and nicotine use disorders for all participants); and significant medical illness. None of the participants was taking psychotropic medication at the time of study participation.

Detailed drug histories were obtained from all participants using the Cannabis Experience Questionnaire (Barkus et al. 2006), structured interview and timeline follow-back (Sobell et al. 1996). Lifetime cannabis use was estimated as the total number of 'spliffs' (cannabis cigarettes; 'joints') consumed. The time taken to smoke an 'eighth' of cannabis (1/8 ounce; about $3.5 \mathrm{~g}$, the standard unit of sale the UK) was chosen as the primary index of cannabis use because this provides a measure of the amount of current drug consumption (shorter time indicating greater consumption). This is likely to be more accurate than subjective recall of the number of spliffs consumed because of variability in cannabis dose between spliffs and inconsistencies in self-reported cannabis use (Akinci et al. 2001).

\section{Cannabis user group}

All cannabis users were recruited by public advertisement. All participants were required to be current, at least weekly, users of cannabis. Cases were primarily recruited from an ongoing cohort study (Morgan et al. 


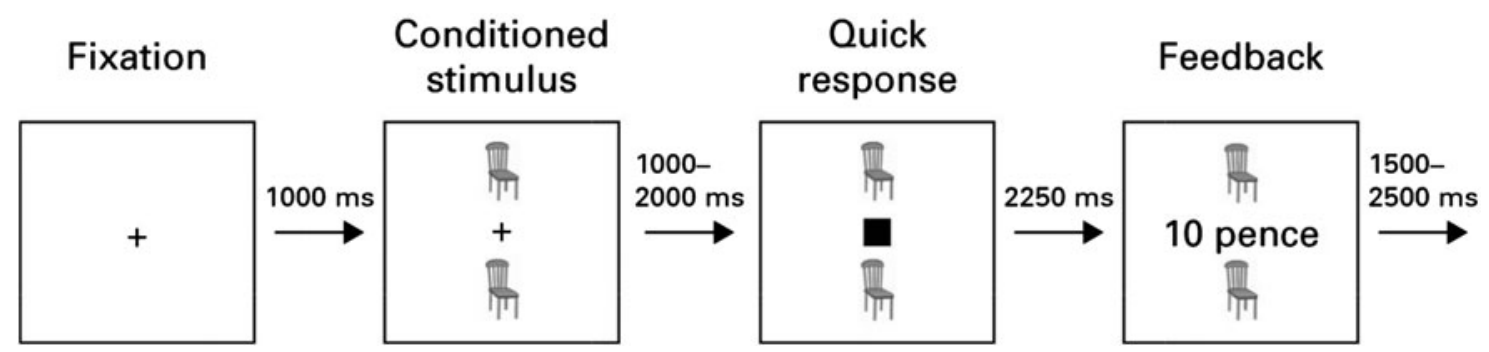

Fig. 1. Salience Attribution Test. Subjects are presented with a fixation cross followed by a cue. They then have to respond to the solid square as quickly as possible. During $50 \%$ of trials, participants are rewarded with money for faster responses, with the probability of the reward signalled by the cue.

2012). A subsample of users had measurements available on the induction of psychotic symptoms in response to smoking cannabis, which was defined as a positive change in scores on the psychotic items of the Psychotomimetic States Inventory (PSI) (Mason \& Wakerley, 2012), measured $5 \mathrm{~min}$ after smoking their usual amount of cannabis (i.e. when acutely intoxicated) compared with when not intoxicated with the drug. These users consumed their own cannabis, and subjective ratings were acquired in the environment where users habitually consumed cannabis (e.g. at home) because drug effects are typically larger in naturalistic as opposed to laboratory environments (Barkus et al. 2006). Cannabis-induced psychotic symptoms abated within $2 \mathrm{~h}$ of consumption. The psychotic items from the PSI covered 'delusional thinking', 'perceptual distortions', 'cognitive disorganization' (thought disorder) and 'paranoia'. Each item was rated on a four-point scale from 'not at all' (score $=0$ ) to 'strongly' (score = 3). Examples of items include: 'People can put thoughts into your mind' and 'You can sense an evil presence around you, even though you cannot see it'. A sample of the cannabis that each participant smoked was taken on the day of testing and analysed for levels of THC (Forensic Science Service, Birmingham, UK).

A total of 12 cannabis users who experienced a positive change in psychotic symptom severity in response to cannabis were recruited from the Bloomfield et al. $(2014 a, b)$ study. An additional two users were recruited from an ongoing study (Morgan et al. 2012). A further three users were recruited by public advertisement. Therefore 17, at least weekly, cannabis users are included in the present study. All cannabis users consumed the drug mixed with tobacco as a spliff.

\section{Control group}

Non-user healthy control participants were recruited from the same geographical area by public advertisement. Controls were required to have no lifetime history of cannabis dependence or abuse (DSM-IV-TR), no more than 10 total uses of cannabis in their lifetime, no report of the induction of psychotic symptoms by cannabis, and no cannabis use in the preceding 3 months. Community surveys indicate that more than $30 \%$ of young adults in England report trying cannabis in their lifetime (Smith \& Flatley, 2012). Control participants were therefore permitted to have had minimal exposure to cannabis to ensure that the control group was representative of the same general population from which the cannabis users were recruited.

\section{$S A T$}

The SAT behaviourally measures aberrant salience. A more detailed description is provided in the original publication (Roiser et al. 2009) and the online Supplementary information. In brief, a cue stimulus appeared on the screen, which could vary across two dimensions: colour (red or blue) and form (animal or household object; Fig. 1). Stimulus features on one dimension predicted reward availability (e.g. red $v$. blue: 87.5 v. $12.5 \%$ ); the other dimension was irrelevant in terms of reward occurrence (e.g. 50\% reward for both animal and household features). Following the cue, participants had to respond to the presentation of a square (the probe) to win money. Faster responses yielded higher rewards, but reward was not always available. If the trial was not reinforced, the message 'Sorry - no money available' was displayed after the probe disappeared. If reinforced, 'hit' responses (made before the probe disappeared) that were slower than the participant's own mean RT (measured during an earlier practice session) resulted in the message 'Hit - good: 10 pence'. For hit responses faster than the participant's mean practice RT the following messages appeared: 'Quick - very good: X pence' and 'Very quick - excellent: $X$ pence'. The maximum reward was $£ 1$. Participants performed the task in two separate blocks of equal length, over which values were averaged.

\section{PET}

PET acquisition and analysis were performed as previously described (Bloomfield et al. 2014a, b) using a 
method that has demonstrated good test-retest reliability (Egerton et al. 2010). In brief, subjects underwent $\left[{ }^{18}\right.$ F]DOPA scanning on an ECAT HR+ 962 tomograph (CTI/Siemens, USA). Participants were asked to fast and abstain from cannabis for $12 \mathrm{~h}$ and to refrain from smoking tobacco for $2 \mathrm{~h}$ before imaging. On the day of PET scanning, urine drug screen (Monitect HC12; Branan Medical Corporation, USA) confirmed no recent drug use (other than cannabis in the user group), and a negative urinary pregnancy test was required in all female participants. A research clinician (M.A.P.B.) assessed psychotic symptoms using the Positive and Negative Syndrome Scale (PANSS) at the time of scanning. No participants had psychotic symptoms at the time of scanning [mean PANSS positive score cannabis users $=7.4$ (s.D. $=0.5$ ); control participants $=7.3$ (s.D. =0.5)]. Participants received carbidopa $150 \mathrm{mg}$ and entacapone $400 \mathrm{mg}$ orally $1 \mathrm{~h}$ before imaging to reduce the formation of radiolabelled $\left[{ }^{18} \mathrm{~F}\right] \mathrm{DOPA}$ metabolites (Cumming et al. 1993; Guttman et al. 1993). We performed a $10 \mathrm{~min}$ transmission scan before radiotracer injection for attenuation- and scatter-correction followed by bolus intravenous injection of approximately 180 $\mathrm{MBq}$ of $\left[{ }^{18} \mathrm{~F}\right] \mathrm{DOPA}$. Emission data were acquired for 95 min over 26 frames. Head movement correction was performed with a wavelet filter (Turkheimer et al. 1999) and mutual information algorithm (Studholme et al. 1996). A summation image was created from each movement-corrected dynamic image using real-time position management (RPM) (Gunn et al. 1997). We then defined standardized regions of interest (ROIs) bilaterally in the whole striatum in Montreal Neurological Institute space (Martinez et al. 2003; Egerton et al. 2010) to create an ROI map. We used statistical parametric mapping software (SPM5; http://fil.ion. ucl.ac.uk/spm) to normalize the ROI map to each individual PET summation image using a template to aid normalization (Howes et al. 2009, 2011). We calculated the influx rate constant of $\left[{ }^{18} \mathrm{~F}\right] \mathrm{DOPA}$ uptake in each ROI relative to the cerebellum $\left[K_{i}^{\text {cer }}\left(\mathrm{min}^{-1}\right)\right]$ using the Patlak graphical analysis adapted for a reference tissue input function (Patlak \& Blasberg, 1985; Hartvig et al. 1991, 1997; Hoshi et al. 1993).

\section{Statistical analysis}

Data were analysed using the Statistical Package for the Social Sciences (SPSS), version 21 (IBM, USA). Demographic data were analysed using independentsamples $t$ tests and $\chi^{2}$ tests. SAT data were analysed using repeated-measures analysis of variance with block (1/2) and probability as within-subject variables and group (cannabis user/control) as the betweensubjects variable. Normality of distributions was assessed using the one-sample Kolmogorov-Smirnov test. Salience outcome measures were assessed for significant skew. RT and visual analogue scale (VAS) aberrant salience scores from the SAT were square root transformed prior to analysis to reduce skew, though untransformed values are presented in the text, figures and tables for clarity. Relationships between salience measures, symptoms and dopamine synthesis capacity were assessed using Pearson's $r$. To determine whether participants consistently assigned aberrant salience to any particular stimulus feature, $\chi^{2}$ tests were employed. For all analyses $p<$ 0.05 (two-tailed) was considered significant.

\section{Results}

\section{Participant characteristics}

The mean age of first cannabis use was 15.5 (s.D. = 2.0) years, and the mean duration of at least weekly use was 5.9 (S.D. $=3.1$ ) years. The mean time taken to smoke an eighth was 8.3 (S.D. $=7.3$ ) days and mean lifetime exposure was 2850 (S.D. $=2447$ ) spliffs. Six users met DSM-IV criteria for cannabis dependence or abuse. Mean time to smoke an eighth was 4.0 (s.D.= 4.3) days in users who met dependency and/or abuse criteria and 11.0 (S.D. $=8.4$ ) days in users who did not meet criteria. A total of 17 control participants were matched to the user group for age ( \pm 5 years) and sex. Participant characteristics are reported in Table 1. Urine drug screens were positive for THC and negative for all other substances (amphetamine, opiates, cocaine, methamphetamine, benzodiazepines) in every cannabis user and negative for all drugs (including cannabis) in every control participant. There was no significant group difference in age or sex.

\section{$S A T$}

Behavioural data are presented in Table 2.

\section{RT (implicit salience)}

Participants responded faster on high- relative to low-probability-reinforced trials $\left(F_{1,31}=21.4, p<0.001\right)$ and there was no group $\times$ probability interaction $\left(F_{1,30}\right.$ $=1.02, p=0.32)$. There was no group $\times$ block interaction $\left(F_{1,32}=0.05, p=0.82\right)$ and no main effect of group $\left(F_{1,32}\right.$ $=1.60, p=0.22)$ or block $\left(F_{1,32}=2.43, p=0.13\right)$. There was a significant probability $\times$ block interaction $\left(F_{1,32}=\right.$ $5.28, p=0.03)$ : across both groups implicit adaptive salience was significantly greater on block 2 than block 1 .

There was no significant difference in implicit aberrant salience between cannabis users and controls $\left(F_{1,32}=1.12, \quad p=0.30\right)$, no group $\times$ block interaction $\left(F_{1,32}=1.08, p=0.31\right)$ and no main effect of block $\left(F_{1,32}=1.30, p=0.26\right)$. Participants did not consistently 
Table 1. Sample characteristics

\begin{tabular}{llll}
\hline & Controls $(n=17)$ & Cannabis users $(n=17)$ & $p^{\mathrm{a}}$ \\
\hline $\begin{array}{l}\text { Mean age, years (S.D.) } \\
\text { Sex, } n\end{array}$ & $23.9(4.2)$ & $22.4(1.9)$ & 0.19 \\
$\quad$ Female & 6 & 3 & 0.44 \\
$\quad$ Male & 11 & 14 & N.A. \\
Mean cannabis use, g cannabis/month (s.D.) & N.A. & $31.8(38.5)$ & N.A. \\
$\begin{array}{l}\text { Mean THC content of cannabis, \% (S.D.) } \\
\text { Mean time to smoke an eighth of cannabis, days (S.D.) }\end{array}$ & N.A. & $7.5(2.9)$ & N.A. \\
Mean age of onset of regular cannabis use, years (S.D.) & N.A. & $16.3(7.3)$ & N.A. \\
\hline
\end{tabular}

S.D., Standard deviation; N.A., not applicable; THC, $\Delta^{9}$-tetrahydrocannabinol.

${ }^{a}$ Independent-samples $t$ tests for variables with normal data distributions; Mann-Whitney $U$ tests for variables with nonnormal data distributions; $\chi^{2}$ tests for dichotomous variables.

Table 2. Salience Attribution Test behavioural data

\begin{tabular}{llcc}
\hline Test & Measure & Controls $(n=17)$ & Cannabis users $(n=17)$ \\
\hline Block 1 & & & $277.5(111.7)$ \\
& RT high probability, ms & $300.5(114.9)$ & $304.2(53.2)$ \\
& RT low probability, ms & $335.8(51.4)$ & $3.8(14.2)$ \\
& RT adaptive salience, ms & $11.2(21.9)$ & $20.8(19.5)$ \\
RT aberrant salience, ms & $12.8(4.7)$ & $63.0(19.0)$ \\
& VAS high probability, mm & $55.8(26.9)$ & $18.0(12.1)$ \\
& VAS low probability, mm & $14.1(8.4)$ & $45.7(25.3)$ \\
& VAS adaptive salience, mm & $41.3(29.4)$ & $10.4(9.6)$ \\
VAS aberrant salience, mm & $16.3(14.5)$ & $294.8(57.5)$ \\
& & $310.8(67.0)$ \\
& RT high probability, ms & $312.9(56.4)$ & $14.9(18.6)$ \\
& RT low probability, ms & $332.7(58.1)$ & $12.4(7.7)$ \\
RT adaptive salience, $\mathrm{ms}$ & $20.3(22.4)$ & $66.3(19.8)$ \\
RT aberrant salience, ms & $13.4(15.2)$ & $10.8(7.6)$ \\
& VAS high probability, mm & $63.3(24.7)$ & $56.0(23.1)$ \\
VAS low probability, mm & $16.3(9.7)$ & $8.4(8.6)$
\end{tabular}

Data are given as mean (standard deviation).

RT, Reaction time; VAS, visual analogue scale; SPQ; Schizotypal Personality Questionnaire.

respond faster in the context of any particular irrelevant stimulus feature $(p>0.05)$.

\section{VAS (explicit salience)}

Across all participants, high-probability-reinforced trials were rated as being more likely to yield reward compared with low-probability-reinforced trials $\left(F_{1,31}\right.$ $=130.0, p<0.001)$. There was no main effect of block $\left(F_{1,32}=3.18, p=0.08\right)$ and no group $\times$ block interaction $\left(F_{1,32}=0.38, p=0.54\right)$. There was no significant effect of group on explicit adaptive salience $\left(F_{1,32}=0.80, p=\right.$ 0.38, Fig. 3).
There was no significant effect of group on explicit aberrant salience $\left(F_{1,32}=1.09, p=0.30\right)$ and no group $\times$ block interaction $\left(F_{1,32}=0.35, p=0.56\right)$ or main effect of block $\left(F_{1,32}=2.43, p=0.13\right)$. Participants did not consistently rate any particular irrelevant stimulus feature as more likely to yield reward relative to the others.

\section{Relationship between salience processing and cannabis use}

Within the cannabis user group, there were no significant relationships between current cannabis use and measures of salience processing (implicit adaptive 


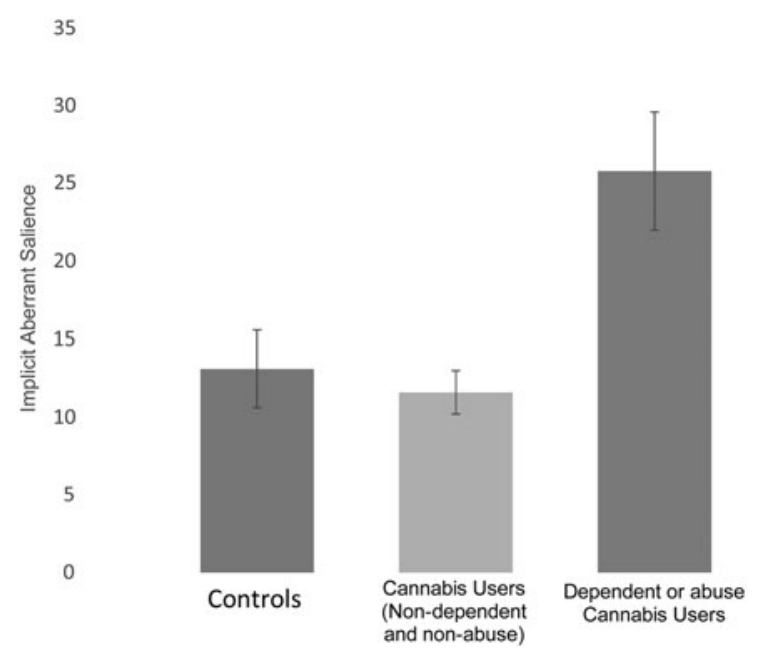

Fig. 2. Implicit aberrant salience (ordinate; $\mathrm{mm}$ ) based in controls and in cannabis users who meet Diagnostic and Statistical Manual of Mental Disorders, fourth edition (DSM-IV) dependency and abuse $(n=6)$, those who did not meet criteria $(n=11)$ and controls. Values are means, with vertical bars representing standard errors.

salience: $r=0.07, p=0.79$; implicit aberrant salience $r=$ $0.49, p=0.06$; explicit adaptive salience $r=-0.46, p=$ 0.07 ; explicit aberrant salience $r=0.14, p=0.61$ ). There was no significant relationship between age of onset of cannabis use and measures of salience processing (implicit adaptive salience: $r=0.32, p=0.23$; implicit aberrant salience $r=-0.18, p=0.52$; explicit adaptive salience $r=-0.12, p=0.66$; explicit aberrant salience $r=-$ $0.12, p=0.65)$.

As an exploratory analysis, to examine whether cannabis dependency and abuse were associated effects of salience processing, the cannabis user group was divided into participants that met DSM-IV-TR criteria for cannabis dependency and/or abuse $(n=6)$ and those who did not meet criteria $(n=11)$. Within the cannabis users there was a significant effect of dependency and abuse diagnosis on implicit aberrant salience, with elevated implicit aberrant salience in the participants meeting dependent or abuse criteria relative to cannabis users not meeting these criteria $\left[F_{1,15}=5.8, p=0.03\right.$, effect size (Cohen's $d$ ) 1.97], but not on the other outcome measures (Fig. 2). However, when the control sample was included in the analysis, the effect of dependency or abuse diagnosis on implicit aberrant salience did not reach the threshold for statistical significance $\left[F_{2,32}\right.$ $=2.9, p=0.07$, effect size (Cohen's $d)=1.39$ ].

\section{Relationship between aberrant salience processing and cannabis-induced psychotic symptoms}

Within the cannabis users, 12 experienced cannabisinduced psychotic symptoms [mean increase in PSI score $=8.6$ (s.D. $=5.6)]$. There was a significant relationship between cannabis-induced psychotic symptom severity and explicit aberrant salience $(r=0.61, p=0.04$; Fig. 3). There were no significant relationships between cannabis-induced psychotic symptoms and the other salience measures $(p>0.05)$, or between Schizotypal Personality Questionnaire score and salience measures $(p>0.05)$.

\section{Relationship between salience processing and dopaminergic function}

As an exploratory analysis, data are presented on salience processing and dopaminergic function. Six controls in the present study had participated in the study of dopaminergic function in cannabis users (Bloomfield et al. 2014a, b). Both implicit and explicit adaptive salience was positively correlated with whole striatal dopamine synthesis capacity, whilst implicit aberrant salience was inversely correlated with whole striatal dopamine synthesis capacity (Fig. 4; Table 3).

Of the cannabis users in the present study, 10 had participated in our previous study of dopaminergic function in cannabis users. There were no significant relationships between the SAT outcome measures and dopamine synthesis capacity in the whole striatum (Table 4). Fisher's $r$-to- $z$ transformation was applied to examine whether differences in the relationships between dopaminergic functioning and salience processing between users and controls were significant (Table 5). Significant differences were found in the relationships between both implicit adaptive and aberrant salience processing and dopamine synthesis capacity in the whole striatum. Specifically, cannabis use was associated with the loss of a positive relationship between implicit adaptive salience and dopamine synthesis capacity, and the loss of an inverse relationship between implicit aberrant salience and dopamine synthesis capacity.

\section{Discussion}

The main finding from this study is that within cannabis users who experienced cannabis-induced psychotic symptoms, there was a significant relationship between cannabis-induced psychotic symptom severity and aberrant salience processing, accounting for $37 \%$ of the variance in psychotic symptom severity. Whilst regular long-term cannabis use was not associated with statistically significant differences in behavioural measurements of salience processing, which is inconsistent with our primary hypothesis, these results show preliminary evidence of increased aberrant salience in cannabis users who meet DSM-IV criteria for 


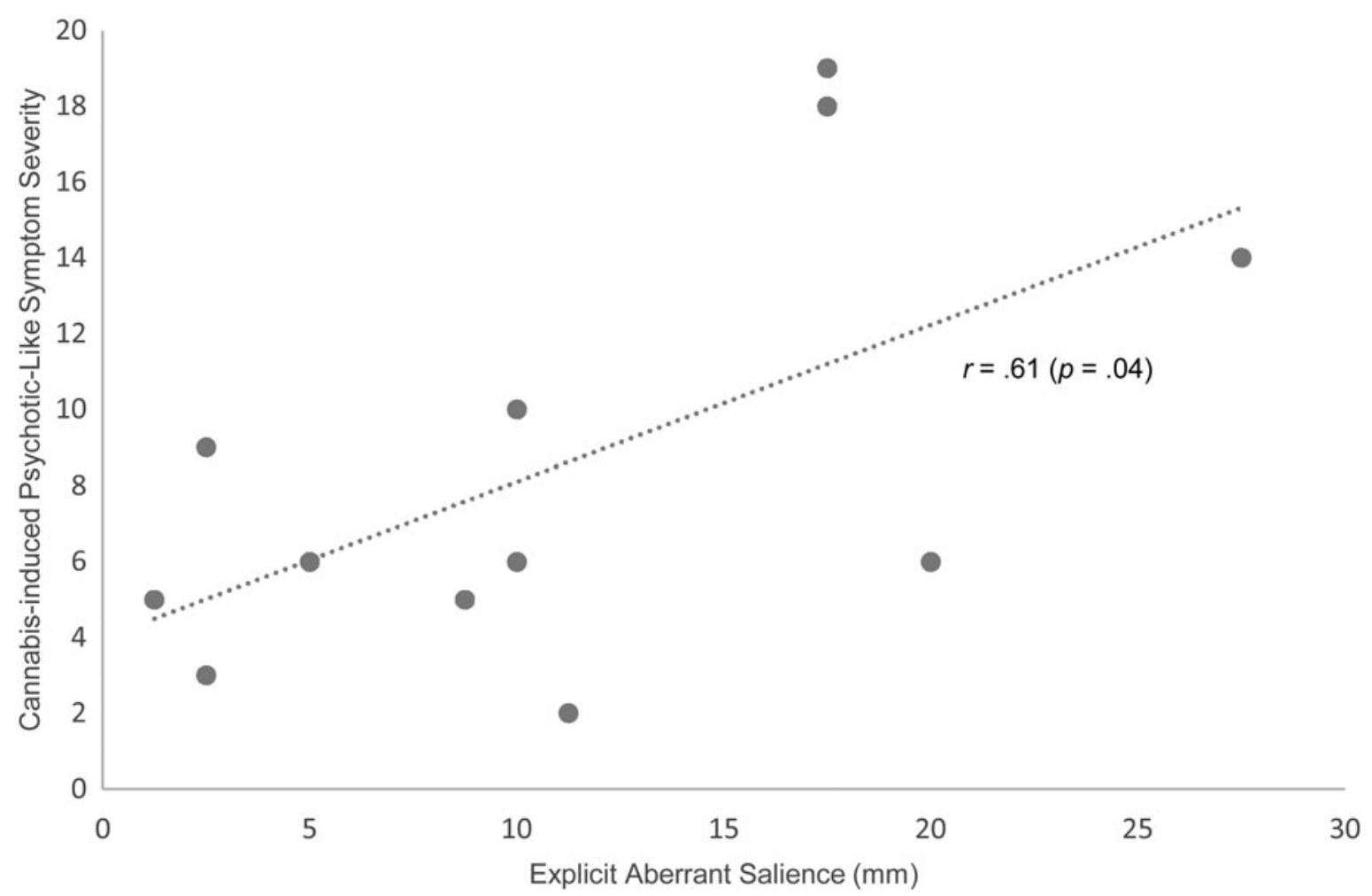

Fig. 3. Relationship between explicit aberrant salience $(\mathrm{mm})$ and cannabis-induced psychotic symptom severity (positive change in Psychotomimetic States Inventory Score).

cannabis abuse or dependence (effect size: Cohen's $d=$ 1.2 ), suggesting that aberrant salience may only become apparent when there is cannabis dependence. In an exploratory analysis, within controls there were positive relationships between both measures of adaptive salience and whole striatal dopamine synthesis capacity, whilst there was an inverse relationship between implicit aberrant salience and whole striatal dopamine synthesis capacity. However, no significant relationships between whole striatal dopamine synthesis capacity and salience processing were observed in cannabis users. The results also indicate a loss of relationship between implicit salience processing and dopamine synthesis capacity in the whole striatum associated with long-term cannabis use.

This is the first study to examine aberrant salience processing in cannabis users. Whilst there was no significant difference in aberrant salience between the cannabis users and controls, a finding of increased implicit aberrant salience in cannabis users who meet DSM-IV-TR criteria for abuse or dependence compared with those who do not suggests that cannabis dependence and abuse are associated with increased aberrant salience. We also found that cannabis-induced psychotic symptom severity and explicit aberrant salience are significantly positively correlated, in line with findings of a positive relationship between explicit aberrant salience and delusion-like symptoms in people at ultra-high risk of psychosis (Roiser et al. 2013) and delusional symptoms in people with schizophrenia (Roiser et al. 2009). In addition, there were some novel findings not predicted by the aberrant salience hypothesis. These were that in healthy controls, whole striatal dopamine synthesis capacity was positively correlated with both measures of adaptive salience processing and negatively correlated with implicit aberrant salience. The finding of opposite relationships between dopamine synthesis capacity and salience processing in healthy controls is not predicted by the aberrant salience hypothesis, where increased dopamine synthesis capacity is predicted to be related to increased aberrant salience and not vice versa. Two studies have assessed previously assessed dopamine synthesis and aberrant salience. One of these did not find significant relationships between the measures (Roiser et al. 2013) and a more recent, larger study, reported a positive relationship between right ventral striatal dopamine synthesis capacity and aberrant salience (Boehme et al. 2015). However, the former study did report that higher dopamine synthesis capacity predicted greater adaptive reward prediction haemodynamic responses in controls, whereas the opposite relationship applied in the individuals at ultra-high risk of psychosis, in line with the findings in control 

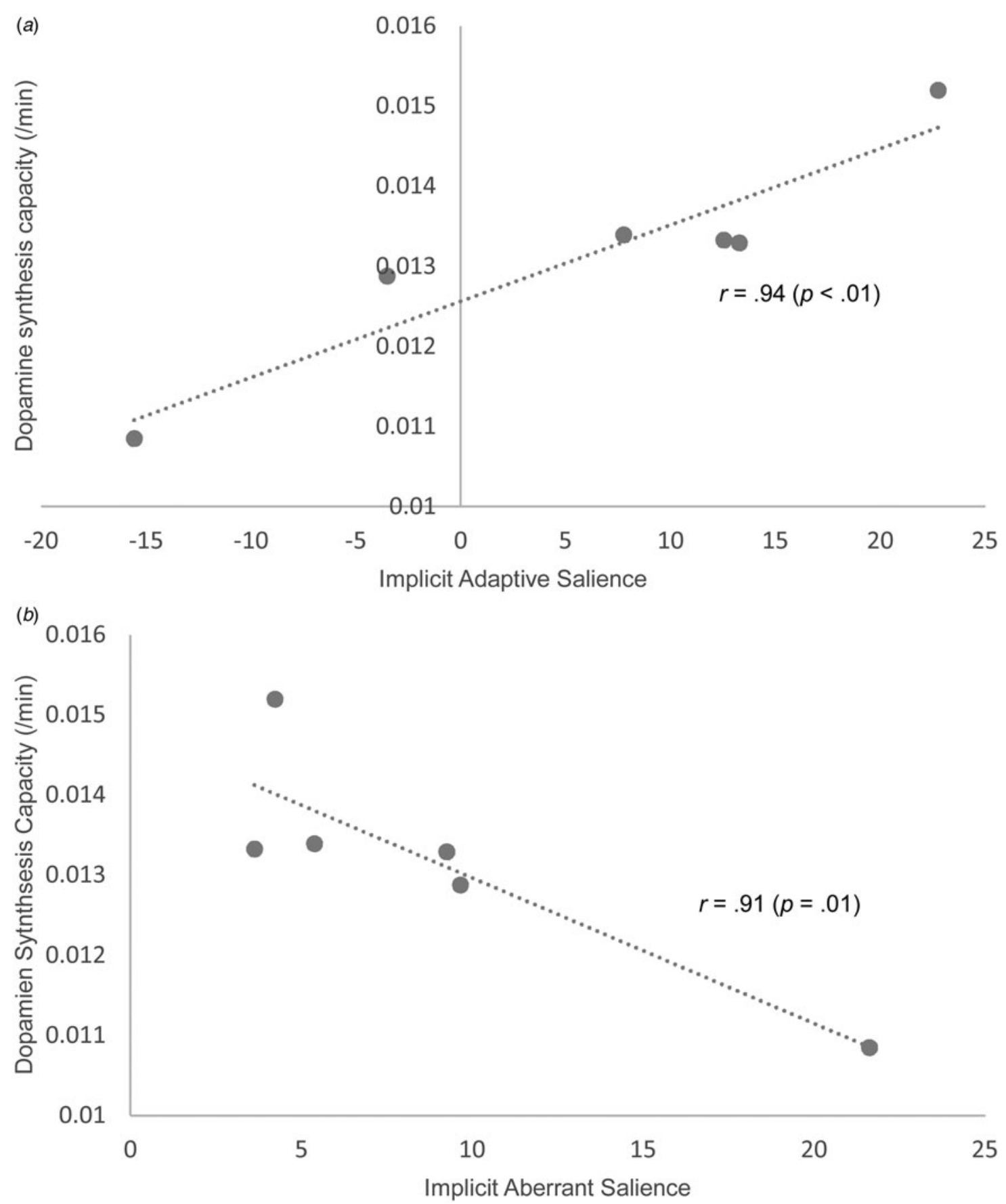

Fig. 4. Relationships between dopamine synthesis capacity (indexed as the influx rate constant $K_{i}^{\text {cer }}$ ) in the whole striatum and implicit adaptive salience $(a)$ and implicit aberrant salience $(b)$ in controls.

participants in the current study. Roiser et al. (2013) speculated that the positive impact of high dopamine synthesis capacity on motivational salience signalling may depend on the baseline state of the dopamine system, such that in healthy volunteers, high dopamine synthesis capacity may facilitate the transmission of motivational salience, potentiating appropriate phasic signals against a background of relatively low gain or tonic dopamine release. Taken together with findings that there is a loss of relationship between implicit salience processing and dopamine synthesis capacity in the whole striatum associated with long-term cannabis use, and given that the mesolimbic dopamine system plays a central role in normal salience processing (Zink et al. 2003) which is modulated by endocannabinoid signalling (Fernandez-Ruiz et al. 2010; Melis \& 
Table 3. Relationships between salience attribution and dopamine synthesis capacity (indexed as $\mathrm{K}_{\mathrm{i}}^{\mathrm{cer}}$ ) in the striatum in controls who had previously undergone PET scans $(\mathrm{n}=6)$

\begin{tabular}{|c|c|c|c|c|c|c|c|c|}
\hline \multirow{2}{*}{$\frac{K_{i}^{c e r}, \min ^{-1}}{\text { Mean (s.D.) }}$} & \multicolumn{2}{|c|}{$\begin{array}{l}\text { RT adaptive } \\
\text { salience }\end{array}$} & \multicolumn{2}{|c|}{$\begin{array}{l}\text { RT aberrant } \\
\text { salience }\end{array}$} & \multicolumn{2}{|c|}{$\begin{array}{l}\text { VAS adaptive } \\
\text { salience }\end{array}$} & \multicolumn{2}{|c|}{$\begin{array}{l}\text { VAS aberrant } \\
\text { salience }\end{array}$} \\
\hline & $r$ & $p$ & $r$ & $p$ & $r$ & $p$ & $r$ & $p$ \\
\hline $0.0132(0.0014)$ & 0.94 & 0.006 & -0.91 & 0.01 & 0.82 & 0.05 & -0.15 & 0.78 \\
\hline
\end{tabular}

$K_{i}^{c e r}$, Influx rate constant; PET, positron emission tomography; RT, reaction time; VAS, visual analogue scale; S.D., standard deviation.

Table 4. Relationships between salience attribution and dopamine synthesis capacity (indexed as $\mathrm{K}_{\mathrm{i}}^{\mathrm{cer}}$ ) in the striatum in cannabis users who had previously undergone PET scans $(\mathrm{n}=10)$

\begin{tabular}{|c|c|c|c|c|c|c|c|c|}
\hline \multirow{2}{*}{$\frac{K_{i}^{c e r}, \min ^{-1}}{\text { Mean (s.D.) }}$} & \multicolumn{2}{|c|}{$\begin{array}{l}\text { RT adaptive } \\
\text { salience }\end{array}$} & \multicolumn{2}{|c|}{$\begin{array}{l}\text { RT aberrant } \\
\text { salience }\end{array}$} & \multicolumn{2}{|c|}{$\begin{array}{l}\text { VAS adaptive } \\
\text { salience }\end{array}$} & \multicolumn{2}{|c|}{$\begin{array}{l}\text { VAS aberrant } \\
\text { salience }\end{array}$} \\
\hline & $r$ & $p$ & $r$ & $p$ & $r$ & $p$ & $r$ & $p$ \\
\hline $0.0128(0.0008)$ & 0.27 & 0.45 & -0.11 & 0.77 & 0.55 & 0.10 & 0.22 & 0.55 \\
\hline
\end{tabular}

$K_{i}^{c e r}$, Influx rate constant; PET, positron emission tomography; RT, reaction time; VAS, visual analogue scale; S.D., standard deviation.

Table 5. Fisher's r-to-z transformation to examine significant differences in the relationships between salience processing and striatal dopamine synthesis capacity in cannabis users and controls

\begin{tabular}{|c|c|c|c|c|c|c|c|c|}
\hline \multirow[b]{2}{*}{ ROI } & \multicolumn{2}{|c|}{$\begin{array}{l}\text { RT adaptive } \\
\text { salience }\end{array}$} & \multicolumn{2}{|c|}{$\begin{array}{l}\text { RT aberrant } \\
\text { salience }\end{array}$} & \multicolumn{2}{|c|}{$\begin{array}{l}\text { VAS adaptive } \\
\text { salience }\end{array}$} & \multicolumn{2}{|c|}{$\begin{array}{l}\text { VAS aberrant } \\
\text { salience }\end{array}$} \\
\hline & $z$ & $p$ & $z$ & $p$ & $z$ & $p$ & $z$ & $p$ \\
\hline Striatum & 2.12 & 0.03 & -2.05 & 0.04 & 0.78 & 0.44 & -0.54 & 0.59 \\
\hline
\end{tabular}

RT, Reaction time; VAS, visual analogue scale; ROI, region of interest.

Pistis, 2012; Melis et al. 2012), this would suggest that long-term cannabis use may give rise to aberrant salience by disrupting dopaminergic salience processing. Alternatively, this may predate the cannabis use, such that these individuals then experience a greater reward from smoking cannabis. Whilst the effects of acute THC on aberrant salience processing using the SAT have yet to be reported in the literature, and the case-control design of this study is not able to infer causality, there is evidence from a study using the oddball task (Bhattacharyya et al. 2012) that THC reduces latency to non-salient $v$. salient stimuli in healthy volunteers, consistent with this interpretation. However, this phenomenon may not be restricted to reward-based learning only, as increased speed and error rates were observed with THC challenge in a learning and episodic memory task (Curran et al. 2002). Nonetheless, long-term cannabis use has been associated with impairments in filtering out nonsalient information during a selective attention task (Solowij et al. 1991) and THC resulted in irrelevant background visual and auditory stimuli becoming more salient during the performance of a visual processing task (D'Souza et al. 2004).

Adolescence is a period of vulnerability to the development of neurocognitive effects associated with cannabis use and there is also growing evidence that cannabis use is associated with multiple cognitive endophenotypes that are in common with schizophrenia such as response inhibition, sustained attention, working memory and executive function (Solowij \& Michie, 2007). Yet, behavioural studies have 
demonstrated that acute THC challenge produces transient, acute psychotic reactions, the extent of which are unrelated to the degree of cognitive impairment or anxiety. There is a large body of evidence describing the vulnerability of adolescents to impaired cognition, across a range of domains, associated with cannabis use (Jager \& Ramsey, 2008). Animal studies indicate that brain $\mathrm{CB}_{1}$ receptor levels peak in early adolescence (Belue et al. 1995) and humans exposed to cannabis in adolescence are more likely to have impaired neurocognitive function than individuals exposed in adult life (Fontes et al. 2011). Furthermore, there is evidence that neurocognitive deficits (such as impaired RTs, attention and memory) associated with adolescent cannabis use can persist after abstinence (Medina et al. 2007). As described by Schmidt \& Roisier (2009) in order to perform the SAT, participants must be able to attend continuously for an extended period, use working memory, learn probabilistic associations and guide responses on the basis of such associations, all of which may be impaired with cannabis use (Pope et al. 2001; Scholes \& Martin-Iverson, 2009). In order to examine whether other cognitive processes (including working memory, sustained attention, probabilistic reversal learning) were influencing measures on the SAT, Schmidt \& Roisier (2009) performed a factor analysis using the SAT with a battery of cognitive tasks. They found that the SAT could dissociate aberrant salience processing from other aspects of reward learning and attention, although adaptive salience and learned irrelevance were associated with each other. It is therefore unlikely that other aspects of cognitive function that are affected by cannabis use are influencing the current results, although these were not verified in the current study. However, the cannabis users in this study had faster RTs than non-users on both high- and low-probability items in both blocks of the SAT, suggesting that generalized psychomotor slowing in cannabis users is unlikely to account for the current results.

A potential limitation of the current study is that participants consumed their own cannabis, rather than a standard preparation. However, individuals were tested whilst intoxicated and the levels of THC in samples of the cannabis participants were using were measured and it was confirmed that the cannabis contained high levels of THC. There was no fixed interval between cannabis exposure and SAT session, meaning that heavier cannabis users may have had a shorter interval between exposure and scan. It therefore remains possible that differences in the time since last cannabis exposure, and therefore acute $v$. chronic effects of cannabis, contribute to the differences between the dependent/abuser and non-dependent groups, rather than dependency and/or abuse per se.
The measures of substance use rely on self-report and it was not possible to independently verify substance use histories beyond ongoing cannabis use in the user group and no recent use of other drugs in all participants.

A recently published study (Bianconi et al. 2016) found differences in cannabis-related experiences between patients with a first episode of psychosis and controls. The authors of that study reported that patients with a first episode of psychosis exhibit a hypersensitivity to cannabis which not only involved frequent 'unpleasant experiences' but also increased 'enjoyable feelings'. The authors hypothesized that that the increased positive reward acted as a reinforcer to increase the risk of developing cannabis dependence and counterbalancing the experience of unpleasant effects. A large randomized, placebo-controlled study found that THC increased paranoia by increasing negative affect (i.e. anxiety) (Freeman et al. 2014). A further limitation of this study would therefore be that measures of anxiety, such as the Beck Anxiety Inventory, were not recorded. However, taken together with the current study, this suggests that heavy cannabis use may result in a combination of aberrant salience, anxiety, paranoia and amotivation (Bloomfield et al. 2014b), which might explain the increased risk of schizophreniform psychosis. Future work should therefore assess the relationships between both longterm cannabis use and acute THC on psychotic symptoms, salience processing, paranoia, amotivation and negative affect in order to examine this hypothesis.

\section{Conclusion}

These results suggest that cannabis dependence and abuse are associated with increased aberrant salience processing, and that within cannabis users there is a positive relationship between explicit aberrant salience and cannabis-induced psychotic symptom severity. There is also evidence that long-term cannabis use is associated with altered relationships between striatal dopamine synthesis capacity and salience processing. Long-term cannabis use may therefore increase the risk of psychotic symptoms by increasing aberrant salience via disrupted striatal dopaminergic processing.

\section{Supplementary material}

The supplementary material for this article can be found at http://dx.doi.org/10.1017/S0033291716002051

\section{Acknowledgements}

We would like to express our sincere thanks to all our participants. This study was funded by a Medical 
Research Council (UK) grant to O.D.H. (grant no. MC-A656-5QD30), a National Institute of Health Research Biomedical Research Council grant to King's College London, and a Medical Research Council (UK) grant to H.V.C. and C.J.A.M. These data were presented at the British Association of Psychopharmacology, the European College of Neuropsychopharmacology and the American College of Neuropsychopharmacology.

\section{Declaration of Interest}

O.D.H. has received investigator-led charitable research funding or has been on the speaker bureau for Astra-Zeneca, BMS, Eli Lilly and Jansenn Cilag. M.A. P.B. holds a National Institute of Health Research (UK) Clinical Lectureship and has received funding from the British Medical Association. Otherwise, the authors reported no biomedical financial interests or potential conflicts of interest.

\section{References}

Akinci IH, Tarter RE, Kirisci L (2001). Concordance between verbal report and urine screen of recent marijuana use in adolescents. Addictive Behaviors 26, 613-619.

Albrecht DS, Skosnik PD, Vollmer JM, Brumbaugh MS, Perry KM, Mock BH, Zheng QH, Federici LA, Patton EA, Herring CM, Yoder KK (2013). Striatal $D_{2} / D_{3}$ receptor availability is inversely correlated with cannabis consumption in chronic marijuana users. Drug and Alcohol Dependence 128, 52-57.

American Psychiatric Association (2005). Diagnostic and Statistical Manual of Mental Disorders, 4th edn, text revision (DSM-IV-TR). American Psychiatric Association: Washington, DC.

Barkus E, Morrison P, Vuletic D, Dickson J, Ell P, Pilowsky L, Brenneisen R, Holt D, Powell J, Kapur S, Murray R (2011). Does intravenous $\Delta^{9}$-tetrahydrocannabinol increase dopamine release? A SPET study. Journal of

Psychopharmacology 25, 1462-1468.

Barkus EJ, Stirling J, Hopkins RS, Lewis S (2006). Cannabis-induced psychosis-like experiences are associated with high schizotypy. Psychopathology 39, 175-178.

Belue RC, Howlett AC, Westlake TM, Hutchings DE (1995). The ontogeny of cannabinoid receptors in the brain of postnatal and aging rats. Neurotoxicology and Teratology 17, 25-30.

Berridge KC, Robinson TE (1998). What is the role of dopamine in reward: hedonic impact, reward learning, or incentive salience? Brain Research Reviews 28, 309-369.

Bhattacharyya S, Crippa JA, Allen P, Martin-Santos R, Borgwardt S, Fusar-Poli P, Rubia K, Kambeitz J, O'Carroll C, Seal ML, Giampietro V, Brammer M, Zuardi AW, Atakan Z, McGuire PK (2012). Induction of psychosis by $\Delta$-tetrahydrocannabinol reflects modulation of prefrontal and striatal function during attentional salience processing. Archives of General Psychiatry 69, 27-36.
Bianconi F, Bonomo M, Marconi A, Kolliakou A, Stilo SA, Iyegbe C, Gurillo Muñoz P, Homayoun S, Mondelli V, Luzi S, Dazzan P, Prata D, La Cascia C, O'Connor J, David A, Morgan C, Murray RM, Lynskey M, Di Forti M (2016). Differences in cannabis-related experiences between patients with a first episode of psychosis and controls. Psychological Medicine 46, 995-1003.

Bloomfield MAP, Morgan CJA, Egerton A, Kapur S, Curran HV, Howes OD (2014a). Dopaminergic function in cannabis users and its relationship to cannabis-induced psychotic symptoms. Biological Psychiatry 75, 470-478.

Bloomfield MAP, Morgan CJA, Kapur S, Curran HV, Howes OD $(2014 b)$. The link between dopamine function and apathy in cannabis users: an $\left[{ }^{18} \mathrm{~F}\right]$-DOPA PET imaging study. Psychopharmacology 231, 2251-2259.

Boehme R, Deserno L, Gleich T, Katthagen T, Pankow A, Behr J, Buchert R, Roiser JP, Heinz A, Schlagenhauf $F$ (2015). Aberrant salience is related to reduced reinforcement learning signals and elevated dopamine synthesis capacity in healthy adults. Journal of Neuroscience 35, 10103-10111.

Bossong MG, van Berckel BN, Boellaard R, Zuurman L, Schuit RC, Windhorst AD, van Gerven JM, Ramsey NF, Lammertsma AA, Kahn RS (2009). $\Delta^{9}$-Tetrahydrocannabinol induces dopamine release in the human striatum. Neuropsychopharmacology 34, 759-766.

Breivogel CS, Childers SR (2000). Cannabinoid agonist signal transduction in rat brain: comparison of cannabinoid agonists in receptor binding, G-protein activation, and adenylyl cyclase inhibition. Journal of Pharmacology and Experimental Therapeutics 295, 328-236.

Cherek DR, Lane SD, Dougherty DM (2002). Possible amotivational effects following marijuana smoking under laboratory conditions. Experimental and Clinical Psychopharmacology 10, 26-38.

Cumming P, Léger GC, Kuwabara H, Gjedde A (1993). Pharmacokinetics of plasma $6-\left[{ }^{18} \mathrm{~F}\right]$

fluoro-L-3,4-dihydroxyphenylalanine $\left[{ }^{18} \mathrm{~F}\right] \mathrm{FDOPA}$ in humans. Journal of Cerebral Blood Flow and Metabolism 13, 668-675.

Curran V, Brignell C, Fletcher S, Middleton P, Henry J (2002). Cognitive and subjective dose-response effects of acute oral $\Delta^{9}$-tetrahydrocannabinol (THC) in infrequent cannabis users. Psychopharmacology 164, 61-70.

D'Souza DC, Perry E, MacDougall L, Ammerman Y, Cooper T, Wu Y-T, Braley G, Gueorguieva R, Krystal JH (2004). The psychotomimetic effects of intravenous $\Delta-{ }^{9}$-tetrahydrocannabinol in healthy individuals: implications for psychosis. Neuropsychopharmacology 29 , 1558-1572.

Egerton A, Demjaha A, McGuire P, Mehta MA, Howes OD (2010). The test-retest reliability of ${ }^{18} \mathrm{~F}$-DOPA PET in assessing striatal and extrastriatal presynaptic dopaminergic function. NeuroImage 50, 524-531.

Felder CC, Veluz JS, Williams HL, Briley EM, Matsuda LA (1992). Cannabinoid agonists stimulate both receptor- and non-receptor-mediated signal transduction pathways in cells transfected with and expressing cannabinoid receptor clones. Molecular Pharmacology 42, 838-845. 
Fernandez-Ruiz J, Hernandez M, Ramos JA (2010). Cannabinoid-dopamine interaction in the pathophysiology and treatment of CNS disorders. CNS Neuroscience and Therapeutics 16, e72-e91.

First MB, Spitzer RL, Gibbon M, Williams JBW (1996). Structured Clinical Interview for DSM-IV Axis I Disorders, Clinician Version (SCID-CV). American Psychiatric Press: Washington, DC.

Foltin RW, Fischman MW, Brady JV, Kelly TH, Bernstein DJ, Nellis MJ (1989). Motivational effects of smoked marijuana: behavioral contingencies and high-probability recreational activities. Pharmacology, Biochemistry, and Behavior 34, 871-877.

Fontes MA, Bolla KI, Cunha PJ, Almeida PP, Jungerman F, Laranjeira RR, Bressan RA, Lacerda ALT (2011). Cannabis use before age 15 and subsequent executive functioning. British Journal of Psychiatry 198, 442-447.

Freeman D, Dunn G, Murray RM, Evans N, Lister R, Antley A, Slater M, Godlewska B, Cornish R, Williams J, Di Simplicio $\mathrm{M}$, Igoumenou $\mathrm{A}$, Brenneisen $\mathrm{R}$, Tunbridge EM, Harrison PJ, Harmer CJ, Cowen P, Morrison PD (2014). How cannabis causes paranoia: using the intravenous administration of 9-tetrahydrocannabinol (THC) to identify key cognitive mechanisms leading to paranoia. Schizophrenia Bulletin 41, 391-399.

French ED (1997). $\Delta^{9}$-Tetrahydrocannabinol excites rat VTA dopamine neurons through activation of cannabinoid CB1 but not opioid receptors. Neuroscience Letters 226, 159-162.

Ginovart N, Tournier BB, Moulin-Sallanon M, Steimer T, Ibanez V, Millet P (2012). Chronic $\Delta^{9}$-tetrahydrocannabinol exposure induces a sensitization of dopamine $D_{2 / 3}$ receptors in the mesoaccumbens and nigrostriatal systems.

Neuropsychopharmacology 37, 2355-2367.

Govaerts SJ, Hermans E, Lambert DM (2004). Comparison of cannabinoid ligands affinities and efficacies in murine tissues and in transfected cells expressing human recombinant cannabinoid receptors. European Journal of Pharmaceutical Sciences 23, 233-243.

Gunn RN, Lammertsma AA, Hume SP, Cunningham VJ (1997). Parametric imaging of ligand-receptor binding in PET using a simplified reference region model. NeuroImage 6, 279-287.

Guttman M, Léger G, Reches A, Evans A, Kuwabara H, Cedarbaum JM, Gjedde A (1993). Administration of the new COMT inhibitor OR-611 increases striatal uptake of fluorodopa. Movement Disorders 8, 298-304.

Hartvig P, Aquilonius SM, Tedroff J, Reibring L, Agren H, Bjurling P, Ulin J, Långström B (1991). Positron emission tomography of L-DOPA utilization in the brains of rhesus monkeys and human volunteers. Acta Radiologica Supplementum 376, 149-150.

Hartvig P, Torstenson R, Tedroff J, Watanabe Y, Fasth KJ, Bjurling P, Longstrom B (1997). Amphetamine effects on dopamine release and synthesis rate studied in the Rhesus monkey brain by positron emission tomography. Journal of Neural Transmission 104, 329-339.

Hoshi H, Kuwabara H, Léger G, Cumming P, Guttman M, Gjedde A (1993). 6- $\left[{ }^{18} \mathrm{~F}\right]$ fluoro-L-DOPA metabolism in living human brain: a comparison of six analytical methods. Journal of Cerebral Blood Flow and Metabolism 13, 57-69.
Howes OD, Bose SK, Turkheimer F, Valli I, Egerton A, Valmaggia LR, Murray RM, McGuire P (2011). Dopamine synthesis capacity before onset of psychosis: a prospective $\left[{ }^{18} \mathrm{~F}\right]$-DOPA PET imaging study. American Journal of Psychiatry 168, 1311-1317.

Howes OD, Montgomery AJ, Asselin MC, Murray RM, Valli I, Tabraham P, Bramon-Bosch E, Valmaggia L, Johns L, Broome M, McGuire PK, Grasby PM (2009). Elevated striatal dopamine function linked to prodromal signs of schizophrenia. Archives of General Psychiatry 66, 13-20.

Jager G, Ramsey NF (2008). Long-term consequences of adolescent cannabis exposure on the development of cognition, brain structure and function: an overview of animal and human research. Current Drug Abuse Reviews 1, 114-123.

Kamien JB, Bickel WK, Higgins ST, Hughes JR (1994). The effects of $\Delta^{9}$-tetrahydrocannabinol on repeated acquisition and performance of response sequences and on self-reports in humans. Behavioural Pharmacology 5, 71-78.

Kapur S (2003). Psychosis as a state of aberrant salience: a framework linking biology, phenomenology, and pharmacology in schizophrenia. American Journal of Psychiatry 160, 13-23.

Kelley BG, Thayer SA (2004). $\Delta^{9}$-Tetrahydrocannabinol antagonizes endocannabinoid modulation of synaptic transmission between hippocampal neurons in culture. Neuropharmacology 46, 709-715.

Kuepper R, Ceccarini J, Lataster J, van Os J, van Kroonenburgh M, van Gerven JM, Marcelis M, van Laere K, Henquet C (2013). $\Delta$ - $^{9}$-Tetrahydrocannabinol-induced dopamine release as a function of psychosis risk: ${ }^{18} \mathrm{~F}$-fallypride positron emission tomography study. PLOS ONE 8, e70378.

Lane SD, Cherek DR (2002). Marijuana effects on sensitivity to reinforcement in humans. Neuropsychopharmacology 26, 520-529.

Lane SD, Cherek DR, Pietras CJ, Steinberg JL (2005). Performance of heavy marijuana-smoking adolescents on a laboratory measure of motivation. Addictive Behaviors 30, 815-828.

Lane SD, Cherek DR, Pietras CJ, Tcheremissine OV (2004). Acute marijuana effects on response-reinforcer relations under multiple variable-interval schedules. Behavioural Pharmacology 15, 305-309.

Martinez D, Slifstein M, Broft A, Mawlawi O, Hwang D-R, Huang Y, Cooper T, Kegeles L, Zarahn E, Abi-Dargham A, Haber SN, Laruelle M (2003). Imaging human mesolimbic dopamine transmission with positron emission tomography. Part II: amphetamine-induced dopamine release in the functional subdivisions of the striatum. Journal of Cerebral Blood Flow and Metabolism 23, 285-300.

Mason O, Wakerley D (2012). The psychotomimetic nature of dreams: an experimental study. Schizophrenia Research and Treatment 2012, 872307.

Medina KL, Hanson KL, Schweinsburg AD, Cohen-Zion M, Nagel BJ, Tapert SF (2007). Neuropsychological functioning in adolescent marijuana users: subtle deficits detectable after a month of abstinence. Journal of the International Neuropsychological Society 13, 807-820. 
Melis M, Muntoni AL, Pistis M (2012). Endocannabinoids and the processing of value-related signals. Frontiers in Pharmacology 3, 7.

Melis M, Pistis M (2012). Hub and switches: endocannabinoid signalling in midbrain dopamine neurons. Philosophical Transactions of the Royal Society B: Biological Sciences 367, 3276-3285.

Mendelson JH, Babor TF, Kuehnle JC, Rossi AM, Bernstein JG, Mello NK, Greenberg I (1976). Behavioral and biologic aspects of marijuana use. Annals of the New York Academy of Sciences 282, 186-210.

Morgan CJA, Gardener C, Schafer G, Swan S, Demarchi C, Freeman TP, Warrington $\mathrm{P}$, Rupasinghe I, Ramoutar A, Tan N, Wingham G, Lewis S, Curran HV (2012). Sub-chronic impact of cannabinoids in street cannabis on cognition, psychotic-like symptoms and psychological well-being. Psychological Medicine 42, 391-400.

Murray RM, Quigley H, Quattrone D, Englund A, Di Forti $\mathbf{M}$ (in press). Traditional marijuana, high potency cannabis and synthetic cannabinoids: increasing risk for psychosis. World Psychiatry.

NIMH Genetics Initiative (1992). Manual for the Family Interview for Genetic Studies (FIGS). National Institute of Mental Health: Rockville, MD.

Paronis CA, Nikas SP, Shukla VG, Makriyannis A (2012). $\Delta^{9}$-Tetrahydrocannabinol acts as a partial agonist/ antagonist in mice. Behavioural Pharmacology 23, 802-805.

Patlak CS, Blasberg RG (1985). Graphical evaluation of blood-to-brain transfer constants from multiple-time uptake data. Generalizations. Journal of Cerebral Blood Flow and Metabolism 5, 584-590.

Petitet F, Jeantaud B, Reibaud M, Imperato A, Dubroeucq MC (1998). Complex pharmacology of natural cannabinoids: evidence for partial agonist activity of $\Delta^{9}$-tetrahydrocannabinol and antagonist activity of cannabidiol on rat brain cannabinoid receptors. Life Sciences 63, PL1-PL6.

Phillips LJ, Yung AR, McGorry PD (2000). Identification of young people at risk of psychosis: validation of personal assessment and crisis evaluation clinic intake criteria. Australian and New Zealand Journal of Psychiatry 34, S164-S169.

Pope HG, Gruber AJ, Hudson JI, Huestis MA, Yurgelun-Todd D (2001). Neuropsychological performance in long-term cannabis users. Archives of General Psychiatry 58, 909.

Roiser JP, Howes OD, Chaddock CA, Joyce EM, McGuire P (2013). Neural and behavioral correlates of aberrant salience in individuals at risk for psychosis. Schizophrenia Bulletin 39, 1328-1336.

Roiser JP, Stephan KE, den Ouden HEM, Barnes TRE, Friston KJ, Joyce EM (2009). Do patients with schizophrenia exhibit aberrant salience? Psychological Medicine 39, 199-209.

Schmidt K, Roisier JP (2009). Assessing the construct validity of aberrant salience. Frontiers in Behavioral Neuroscience 3, 58.

Scholes KE, Martin-Iverson MT (2009). Cannabis use and neuropsychological performance in healthy individuals and patients with schizophrenia. Psychological Medicine 40, 1635-1646.
Shen M, Thayer SA (1999). $\Delta^{9}$-Tetrahydrocannabinol acts as a partial agonist to modulate glutamatergic synaptic transmission between rat hippocampal neurons in culture. Molecular Pharmacology 55, 8-13.

Sim LJ, Hampson RE, Deadwyler SA, Childers SR (1996). Effects of chronic treatment with $\Delta^{9}$-tetrahydrocannabinol on cannabinoid-stimulated $\left[{ }^{35} \mathrm{~S}\right] \mathrm{GTP} \gamma \mathrm{S}$ autoradiography in rat brain. Journal of Neuroscience 16, 8057-8066.

Smith K, Flatley J (2012). Drug Misuse Declared: Findings from the 2010/11 British Crime Survey (England and Wales). Office of National Statistics, Home Office: London.

Sobell LC, Brown J, Leo GI, Sobell MB (1996). The reliability of the alcohol timeline followback when administered by telephone and by computer. Drug and Alcohol Dependence 42, 49-54.

Solowij N, Michie PT (2007). Cannabis and cognitive dysfunction: parallels with endophenotypes of schizophrenia? Journal of Psychiatry and Neuroscience 32, 30-52.

Solowij N, Michie PT, Fox AM (1991). Effects of long-term cannabis use on selective attention: an event-related potential study. Pharmacology, Biochemistry, and Behavior 40 683-688.

Stiglick A, Kalant H (1983). Behavioral effects of prolonged administration of $\Delta^{9}$-tetrahydrocannabinol in the rat. Psychopharmacology 80, 325-330.

Stokes P, Mehta M, Curran H, Breen G, Grasby P (2009). Can recreational doses of THC produce significant dopamine release in the human striatum? NeuroImage 48, 186-190.

Studholme C, Hill DLG, Hawkes DJ (1996). Automated 3-D registration of MR and CT images of the head. Medical Image Analysis 1, 163-175.

Turkheimer FE, Brett M, Visvikis D, Cunningham VJ (1999). Multiresolution analysis of emission tomography images in the wavelet domain. Journal of Cerebral Blood Flow and Metabolism 19, 1189-1208.

United Nations Office on Drugs and Crime (2010). World Drug Report. United Nations: New York.

Urban NBL, Slifstein M, Thompson JL, Xu XY, Girgis RR, Raheja S, Haney M, Abi-Dargham A (2012). Dopamine release in chronic cannabis users: a $\left[{ }^{11} \mathrm{C}\right]$ raclopride positron emission tomography study. Biological Psychiatry 71, 677-683.

van Hell HH, Vink M, Ossewaarde L, Jager G, Kahn RS, Ramsey NF (2010). Chronic effects of cannabis use on the human reward system: an fMRI study. European Neuropsychopharmacology 20, 153-163.

Volkow ND, Wang GJ, Telang F et al. (2014). Decreased dopamine brain reactivity in marijuana abusers is associated with negative emotionality and addiction severity. Proceedings of the National Academy of Sciences USA 111, E3149-E3156.

Wachtel SR, ElSohly MA, Ross SA, Ambre J, de Wit H (2002). Comparison of the subjective effects of $\Delta^{9}$-tetrahydrocannabinol and marijuana in humans. Psychopharmacology (Berlin) 161, 331-339.

Zink CF, Pagnoni G, Martin ME, Dhamala M, Berns GS (2003). Human striatal response to salient nonrewarding stimuli. Journal of Neuroscience 23, 8092-8097. 